\title{
TÉCNICA PARA O ESTUDO GRANULOMÉTRICO DA FRAÇÃO AREIA DOS SOLOS ( $\left.{ }^{1}\right)$
}

Jose Pereira de Queroz NetTo, engenheiro-agrônomo, Seção de Agro: geologia, Instituto Agronômico.

\section{RESUMO}

Neste trabalho é apresentada uma técnica para o estudo granulométrico da fraçăo areia, sua expressão numérica, representação gráfica e análise estatística.

Foi feito um ensaio preliminar para verificar a partir de que tempo de peneira. gem os resultados obtidos se mostravam reprodutíveis. Os tempos de 10,20 e 30 minutos deram resultados pràticamente iguais, revelando também ser pequeno o êrro devido a outros fatôres.

A aplicação do método de estudo à fraçăo areia de solos provenientes dos arenitos Bauru e Botucatu, do planalto de 8ão Carlos e da Serra de Santana, permitiu eviden. eiar uma diferença flagrante das distribuiçôes granulométricas respectivas. $0 \mathrm{em}$ prêgo da representaçăo gráfiea ressaltou o caráter dessas diferenças, confirmadas pelos resultados da análise estatística.

O solo do arenito Botueatu apresenta uma distribuição mais regular, com menor amplitude. A amplitude cresee para os solos da Serra de Santana e planalto de São Carlos e para o arenito Bauru. Nesta altima amostra a distribuição é mais regular que naquelas duas.

Em relação à moda, os resultados acusam maior quantidade de fraçāo grosseira nas amostras da Serra de Santana e do planalto de São Carlos, maior predominância de fraçōes finas no arenito Bauru. No arenito Botucatu as duas fraçōes estão mais próximas, predominando ainda a areia fina.

Apesar das restriçōes da expressão dos resultados ponderais em freqüência numé. rica, o método revelou-se eficiente na comparação da distribuição granulométrica da fraȩão areia de solos provenientes de diversas formạ̧ōes sedimentares.

\section{1 - INTRODUÇÃO}

A análise do aspecto, das dimensões e da composição do material intemperizado permite, ao lado da paleontologia e do estudo das civilizagões pré-históricas, interpretar de forma mais correta as ações do meio sôbre as formações superficiais e a gênese dos sedimentos. Os estudos geológicos, pedológicos, de relêvo ete., dependem de um conhecimento

(1) Trabalho apresentado e aprovado no 8.0 Congresso Brassileiro de Ciência do Solo, realizado de 15 a 30 de julho de 1961, em Belém do Pará. Recebido para publicaçōo em 2 de outubro de 1962. 
preciso da ação do clima, pela apreciação do seu efeito sôbre as forma-
ções superficiais.

A intensidade e duração dos fenômenos de alteração e decomposição serão refletidos pela ausêneia ou presença de elementos do material original, por exemplo, fragmentos de rocha, e pela ausência ou presenȩa de elementos formados secundàriamente: argilas, conereções, nódulos etc. Assim, as dimensões dos grãos correspondem, geralmente, a uma composição mineralógica aproximada $(1,4)$. Acima de 3 a $4 \mathrm{~mm}$, os grãos representam restos da rocha, formados de vários minerais. Abaixo dêsse limite dimensional, o material é formado quase exclusivamente por minerais, sendo perdominantemente quartzoso abaixo de $2 \mathrm{~mm}$. Abaixo de 0,002 $\mathrm{mm}$ predominam as argilas e os óxidos metálicos, em diferentes graus de hidratação. Conseqüientemente, a composição química é mais complexa nos extremos dessa variação dimensional.

Dessa maneira, o estudo granulométrico e mineralógico dos solos, além de ligá-los às rochas que lhes deram origem, podem ainda fornecer indicações sôbre o regime morfoclimático atuante $(\mathbf{3})$.

A granulometria é essencialmente o estudo da repartição dos grão por categoria de tamanho. Segundo Pettijohn (8), os propósitos da análise granulométrica são vários :

1. - Propor classificação para nomear com precisão os sedimentos.

2 - Estudar a influêneia do tamanho dos grãos na porosidade e permeabilidade.

3 - Estudar as relações entre a dinâmica do agente transportador e. 0 transporte das partículas.

4 - Estudos quantitativos sôbre o facies e problemas correlatos. dimentos.

$\check{5}-$ Identificação do agente ou responsável pela origem dos se-

No presente trabalho são estudadas a técnicu da análise granulométrica e a sua eficiência na distinção de alguns solos provenientes de formaçōes arenosas diversas do Estado de São Paulo.

\section{2 - MATERIAL E MÉTODO}

Utilizaram-se solos provenientes do arenito Bauru, do arenito Botucatu, dos sedimentos da Serra de Santana e do planalto de São Carlos. Analisando certos perfis, pôde-se verificar que, a partir de determinada profundidade, as distribuições granulométricas e as curvas acumulativas eram constantes (3), estando essas profundidades indicadas no quadro 2, para cada amostra. 
As aberturas das malhas, em milímetros, do jôgo de peneiras adotado, estão indicadas nos quadros 1 e 2. Essa escala de abertura de malhas permite :

1 - Obter as porcentagens de areia grossa e areia fina, de acôrdo com a escala internacional de Atterberg.

2 - Representar, gràficamente, em escala logarítmica por pontos regularmente espaçados, por variarem as dimensões em progressão geométrica, cuja razão é $\sqrt{2}$ (1).

\section{1 - NATUREZA DOS ERROS DA ANÁliSE GRANULOMÉTRICA}

Segundo L. Berthois (1) os erros da análise granulométrica são devidos a :

erros da amostragem;

deformação e obstrução das malhas das peneiras;

perdas de material durante o processo;

erros de pesagem;

efeito do atrito ou quebramento.

A retirada de amostras no local é uma operação delicada e que deve ser efetuada com bastante rigor $(\mathbf{1}, \mathbf{8}, \mathbf{9}, \mathbf{1 0})$. Devem-se delimitar exatamente as camadas, principalmente seguindo as variações de textura, anotando tôdas as características encontradas, devendo cada amostra representar fielmente cada camada. A quantidade de material a ser retirada é condicionada pelo tamanho máximo dos grãos e pela heterogeneidade: quanto maior a quantidade de elementos grosseiros, tanto mais importante ela deverá ser.

Para a peneiragem, utiliza-se uma subamostra, também dependente do tamanho dos grãos, da heterogeneidade do material e da precisão a ser obtida na operação. Quando o tamanho máximo dos grãos não ultrapassa 2 a $3 \mathrm{~mm}$, pode-se operar com $100 \mathrm{~g}$, não importando a heterogeneidade do material. Se aparece uma quantidade grande de elementos grosseiros, a amostra é passada na peneira de $2 \mathrm{~mm}$ de abertura de malha e, se a fração menor não ultrapassar $200 \mathrm{~g}$, será utilizada integralmente (1).

Os erros devidos à deformaçāo e obstrução das malhas das peneiras, as perdas de material durante o processo e os efeitos do atrito ou quebramento, dizem respeito à operação da peneiragem pròpriamente dita. 
Para que exista a probabilidade de todcs os grãos entrarem em contato com as malhas, é necessário que a quantidade retida por uma peneira de $20 \mathrm{~cm}$ de diâmetro seja inferior a $40 \mathrm{~g}(\mathbf{1}, \mathbf{1 0})$. A obstrução das malhas é causada por um certo número de grãos, cujo diâmetro é semelhante à abertura, e pela existência de grãos irregulares ou compridos, que a prolongação da operação da peneiragem aumenta a probabilidade de passagem. Os erros, nesse caso, são condicionados pelo número de aberturas da peneira e pela quantidade de grãos capazes de obstruíla. Um êrro de $0,1 \mathrm{~g}$ é menos perceptível nas peneiras de grande abertura de malha: numa peneira de $10 \mathrm{~cm}$ de diâmetro e $0,500 \mathrm{~mm}$ de abertura de malha, bastaria que uma malha em 500 fôsse obstruída (1). Assim, há necessidade de uma inspeção rigorosa após a operação. Nas peneiras mais finas o êrro é distinguido mais fàcilmente, porém a desobstrução é mais difícil e a malha mais sujeita à deformação.

Para areias quartzosas, a possibilidade de ocorrência de efeito secundário de quebramento dos grãos por choque é pequena, mesmo em peneiragens prolongadas. Porém, se a composição mineralógica é heterogênea, se ocorrem micas ou elementos organógenos, o quebramento dos grãos torna-se causa de êrro importante. L. Berthois (1) recomenda 0 tempo de 15 minutos para as areias quartzosas, ou mesmo feldspáticas, e 10 minutos para os outros tipos. Outros autores $(\mathbf{1 0})$, limitam o tempo de peneiragem a 10 minutos, independentemente da composição mineralógica.

A duração da peneiragem deve ser suficientemente longa para permitir que todos os grãos entrem em contato com a malha, porém não pode ser prolongada em excesso, para evitar o efeito do quebramento, pelo atrito ou choque, e a obstrução das malhas (1).

\section{2 - MARCHA ANALATICA}

A análise granulométrica foi feita no material sêco ao ar, passado na peneira de $2 \mathrm{~mm}$, o que além de fornecer um material homogêneo, permitiu trabalhar com subamostras de $100 \mathrm{~g}$.

Para obter uma subamostra representativa deveria ser utilizado um separador-fracionador mecânico (1). Na sua falta, usoul-se uma bandeja metáliea onde se colocou tôda a amostra, numa camada regular não muito espêssa. Com uma pequena colher e por pequenos golpes ao acaso, retirou-se a quantidade necessária para perfazer $100 \mathrm{~g}$. 
O limite inferior da abertura da malha deve ser fixado em $0,053 \mathrm{~mm}$ ou, mesmo, em $0,074 \mathrm{~mm}$. Abaixo dêsses limites dimensionais a peneiragem torna-se laboriosa e os resultados menos precisos, além da lei de Stokes começar a ser válida para as partículas inferiores a $0,080 \mathrm{~mm}$, podendo ser utilizada então na determinação de suas quantidades.

A separação das frações finas, argila e s lte, foi feita por decantação após dispersão e agitação, obedecendo acs moldes em uso na Seção de Agrogeologia (6). Um amostra foi passada a úmido na peneira de $0,037 \mathrm{~mm}$ de abertura de malha, tendo sido desprezados os grãos menores. A quantidade de areia obtida dessa maneira foi quase igual ao total, pois, a amostra era pobre em frações finas intermediárias.

A areia, livre de argila e silte, foi então colocada no conjunto de peneiras, sendo estas adaptadas a um aparelho do tipo Ro-tape. $O$ aparelho utilizado comportava sòmente 6 peneiras, obrigando a operar em duas vêzes. $O$ tempo de peneiragem foi de 15 minutos e as frações recolhidas sôbre cada peneira foram pesadas separadamente. 0 êrro, por perdas ou manipulação; foi mínimo; como se pode constatar nos quadros 1 e 2, onde são apresentados os resultados da análise, juntamente com os totais obtidos pela pesagem da areia antes da peneiragem, à esquerda, e por soma das frações recolhidas, à direita.

\section{3 - TEMPO DE PENEIRAGEM}

Para ajuizar da influência do tempo de peneiragem sôbre os resultados, foram feitos alguns ensaios preliminares que constam do quadro 1.

1 - Uma amostra foi peneirada durante 10,20 e 30 minutos ( $T$ $-2561)$.

2 - Outra amostra foi peneirada durante 30 minutos, pesando-se a cada 10 minutos a quantidade de material retido pelas peneiras, sendo êle então reposto na peneira correspondente; obtiveram-se, assim, os tempos de peneiragem de 10 minutos, $10+10=20$ minutos e $10+10+$ $10=30$ minutos $(T-2606)$.

Tanto num processo como noutro, os resultados foram muito semelhantes, principalmente em porcentagens acumuladas. A maior varia̧̧ão ocorreu nas peneiras que retêm maior quantidade de grãos, nunca atingindo, porém, o êrro admissível na análise (1). Baseados nesses resultados, adotou-se o tempo de peneiragem de 15 minutos. 


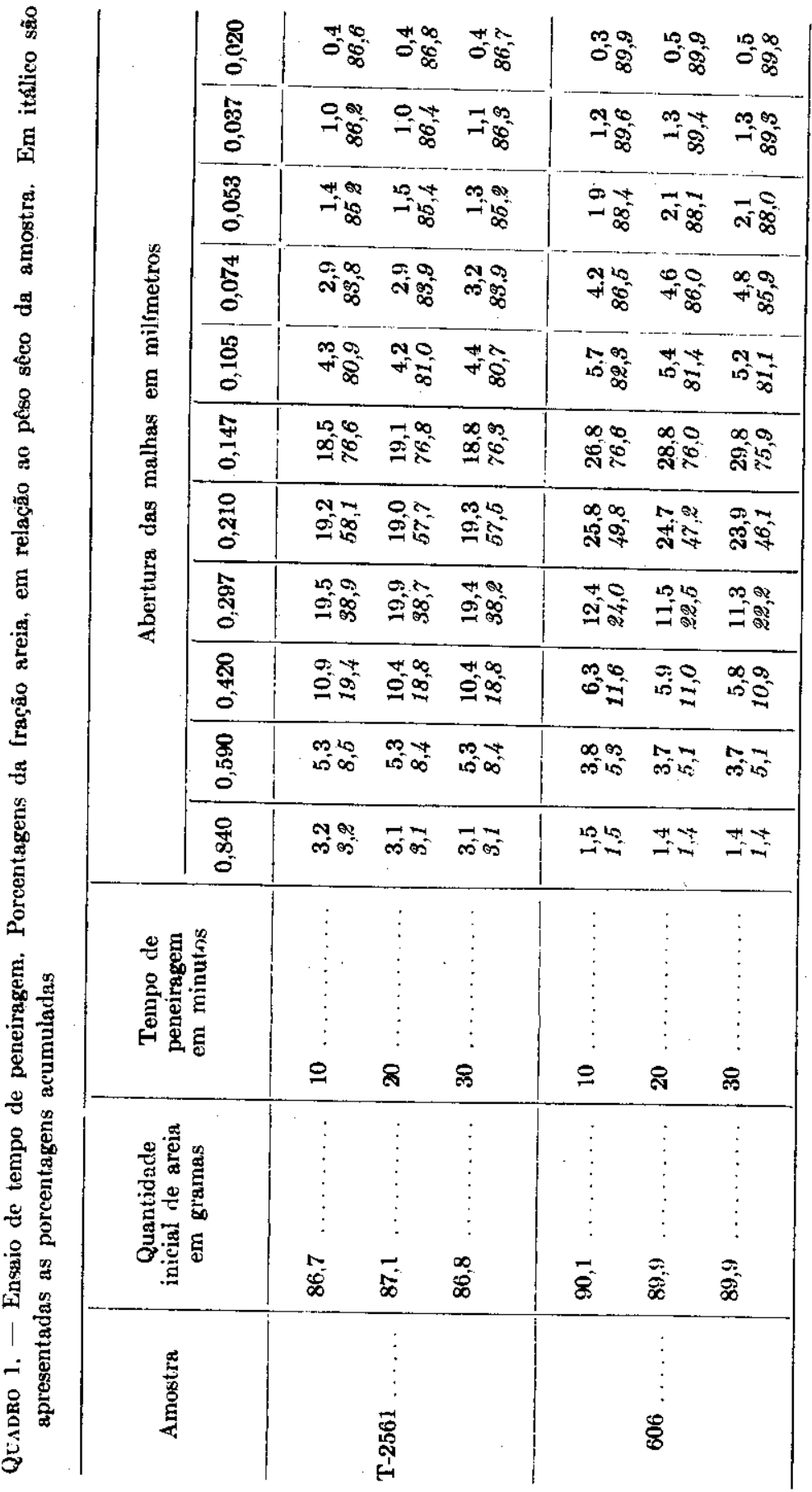




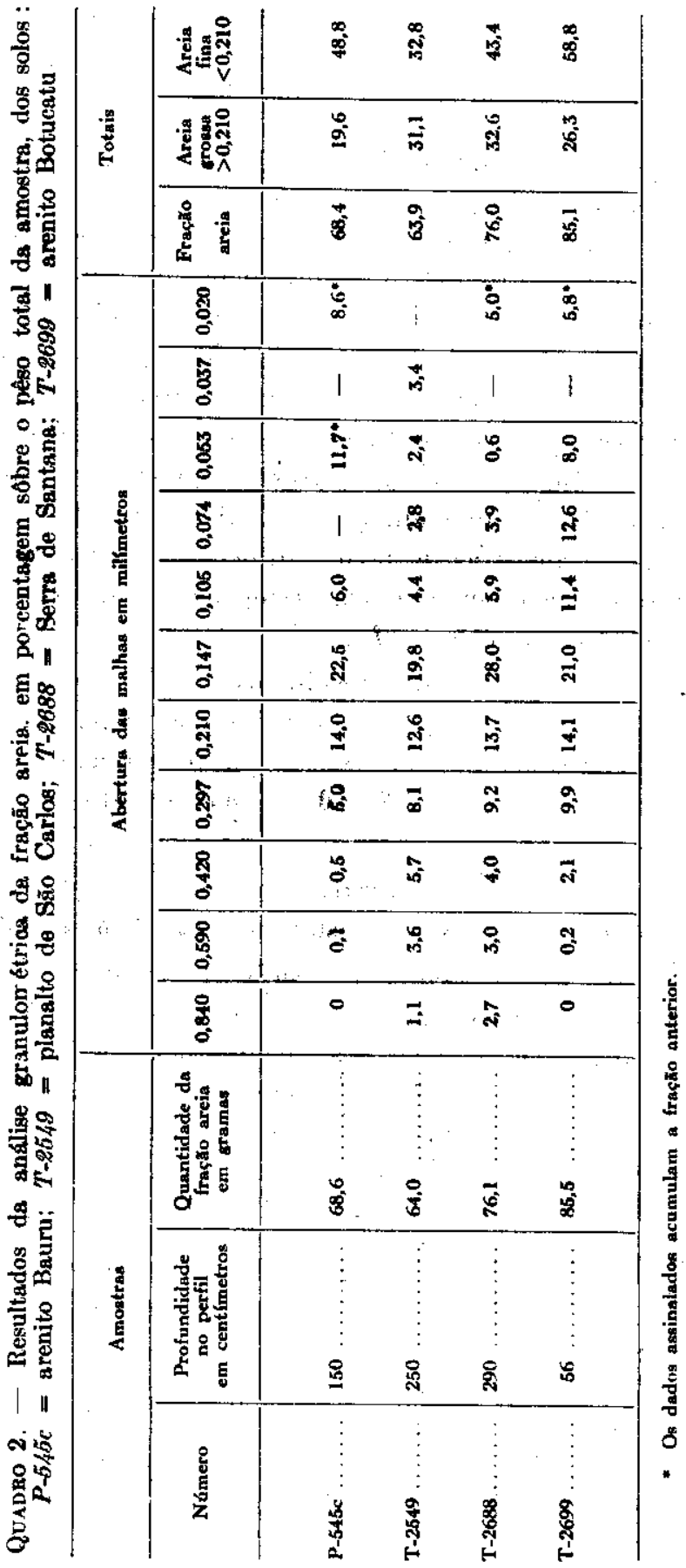




\section{3 - RESULTADOS E DISCUSSAO}

\section{1 - REPRESENTAÇÃO DOS RESULTADOS}

A expressão dos resultados da análise granulométrica em freqüência ponderal admite que o pêso da areia, que constitui o resíduo de uma peneira, representa a expressão da freqüência (quadros 1 e 2). Essa expressão apresenta, entretanto, o inconveniente de considerar que uma partícula grosseira, de pêso determinado, seja o equivalente sedimentar de um certo número de partículas menores. Essse fato não pode ser justificado por nenhuma consideração de ordem hidrodinâmica, como se vê no exemplo fornecido por L. Berthois (1): 0,1 $\mathrm{g}$ de sedimentos quartzosos podem conter 15 grãos de diâmetros compreendidos entre 2,062 e $1,458 \mathrm{~mm}$, ou 42.000 compreendidos entre 0,129 e $0,091 \mathrm{~mm}$. Todavia, quando se trata de amostras de pêso considerável, os métodos de transformação da freqüência ponderal em freqüiência numérica, são por demais laboriosos e impraticáveis (1).

A representação gráfica dos resultados é feita por histogramas e eurvas acumulativas, nas quais as dimensões das malhas, em escala logarítmica, são colocadas nas abcissas e as porcentagens, simples ou acumuladas, nas ordenadas $(\mathbf{1}, \mathbf{8}, \mathbf{1 0})$, como se pode ver nas figuras anexas.

Uma forma cômoda de visualizar, numèricamente, o comportamento da amostra é o emprêgo da análise ếstatística $(2,3,5,8,10)$.

Determinou-se, gràficamente, a posição da mediana, $M$, na interseção da curva com a linha dos $50 \%$, representando o diâmetro acima e abaixo do qual são encontrados exatamente $50 \%$ do material. $O$ primeiro quartel $\left(Q_{1}\right)$ corresponde, por convenção, ao diâmetro que tem $75 \%$ dos grãos maiores e $25 \%$ menores do que êle, ao passo que o diâmetro do terceiro quartel $\left(Q_{s}\right)$ tem $25 \%$ de grãos maiores e $75 \%$ menores do que êle.

Os outros valôres da análise estatística são:

1) $O$ desvio aritmético dos quartéis, $Q D a=\left(Q_{3}-Q_{1}\right) / 2$, que expressa o afastamento entre os quartéis e a mediana;

2) $O$ coeficiente de seleção, $S o=\sqrt{Q_{s} / Q_{1}}$. Se o índice de seleģão fôr menor que 2,5, a amostra pode ser considerada bem selecionada; se fôr maior que 4,5, é mal selecionada; a seleção normal corresponderia ao índice 3,00 ; 
3) $O$ grau aritmético de simetria, $S k a=\left(Q_{1}+Q_{3}-2 M\right) / 2$. Se fôr igual a zero, o total da granulação compreendida entre o $1 .^{\circ}$ e $03 .^{\circ}$ quartéis possui a mediana equidistante dos dois extremos;

$\left.4^{\circ}\right) 0$ grau geométrico de assimetria, $S k=\left(Q_{t} \times Q_{s}\right) / M_{2}$. Quando $S k=1$, a mediana coineide com a moda, isto é, com o valor mais freqüente da distribuição. dro 3 .

Os diversos valôres da análíe en futica podem ser vistos no qua-

Quadro 3. - And́lise estatística apliceda à granulometrir dos solos: $P-545 \mathrm{r}=$ arenito Bauru; $T-2549=$ planalto de São Carlos; $T-2688=$ Serra de Santana; $T-269.9=$ $=$ arenito Botucatu. $M=$ mediana; $Q_{3}=3 .^{\circ}$ quartel; $Q_{1}=1 .^{\circ}$ quartel; So $=$ = coeficiente de seleção: $\sqrt{Q_{8} Q_{1}} ; Q D a=$ desvio aritmético dos quartéis: $\left(Q_{8}-Q_{1}\right) / 2$; $S k a=$ grau aritmético de simetriła $\left.Q_{Q_{1}}+Q_{3} \ldots 2 M\right)(2 ; S k=$ grau geométrico de simetria: $\left(Q_{1} \times Q_{3}\right) / M^{2}$

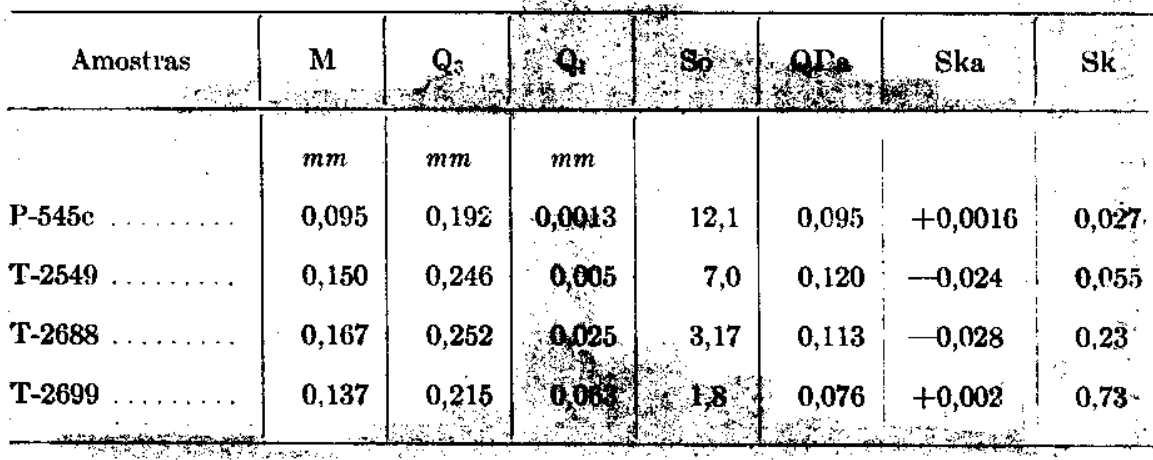

\section{$3.2 \sim$ DISCUSSAO DOS RESULTADOS}

No quadro 2 estão representados os resultados da análise granulométrica : a amostra $P$-545c refere-se um perfil da Estação Experimental de Pindorama, no arenito Bauru ( $)$; a amostra $T-2549$ foi retirada no planalto de São Carlos, no erenito Bauru (3); a amostra $T-2688$ foi retirada na Serra de Santana $(3)$, a mostra $T-2699$ pertence a um perfil do arenito Botueatu, no km 188,4 da rodovia Washington Luiz (3).

O exame dos histogramas (figura 1) revela uma diferença sensivel entre a amostra $T$-2699 e as outras; sua fração areia apresenta grãos mais grossos e mais finos que a moda $(0,147$ a 0,210$)$ bastante bem repartidos. Nas outras, a distribuição é menos regular, porém, sòmente a amostra $P-545 c$ contém uma fração fina mais importante do que as outras.

Pode-se observar, também, que as amostras $P-545 c$ e $P$-269.9 não apresentam, pràticamente, grãos maiores que $0,590 \mathrm{~mm}$, ao contrário das outras duas, principalmente $T-2688$, que contém ainda uma quantidade razoável de grãos maiores que $0,840 \mathrm{~mm}$. 


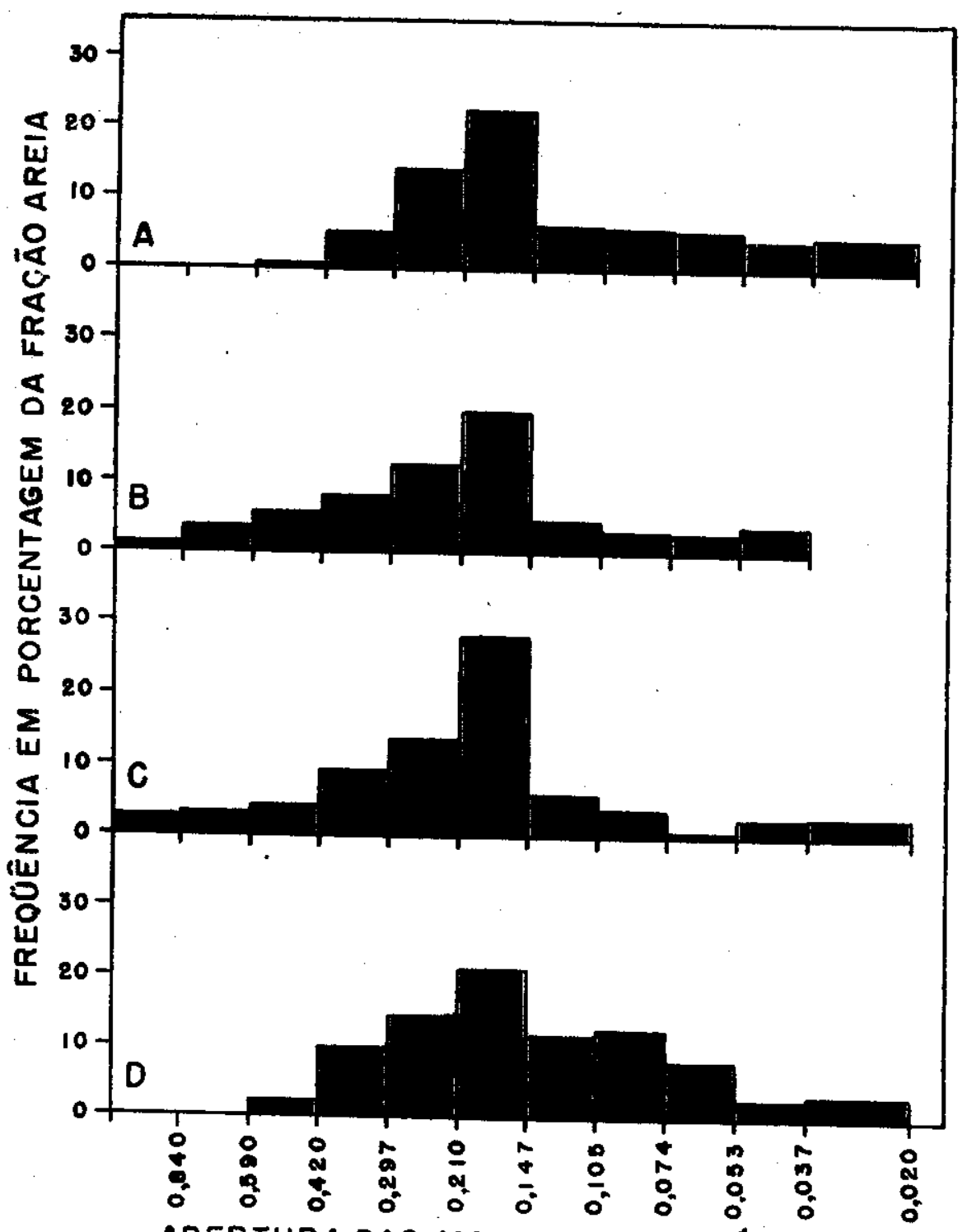

ABERTURA DAS MALHAS EM MILÍMETROS

Figura 1. - Diatribuị̧o granulométriç da fração areia de alguns tipos de solo do Estado de São Paulo: A) P.545e - arenito Bauru da Estaçāo Experimental de Pindorama; $B$ ) T.2549 - planalto de São Carlos; $C$ ) T-2688 - Serra de Santana: I) T.2699 - arenito Botueatu. 
Outro fato que ressalta do exame dos histogramas é a posição da moda, localizada em todos os casos na fração $0,147-0,210 \mathrm{~mm}$, que na amostra $T-2688$ sobressai com maior nitidez.

As curvas acumulativas (figura 2) repetem algumas das observações feitas para os histogramas : a representação da amostra $T-26.99$ é mais regular, não apresentando a quebra brusca causada pela rarefação da fração fina. Essa quebra é menor para a amostra $P-545 c$ do que para as duas restantes, mostrando melhorar a distribuição na fração fina. As frações grosseiras nas amostras $T-2549$ e $T-2688$ também apareeem com bastante evidência.

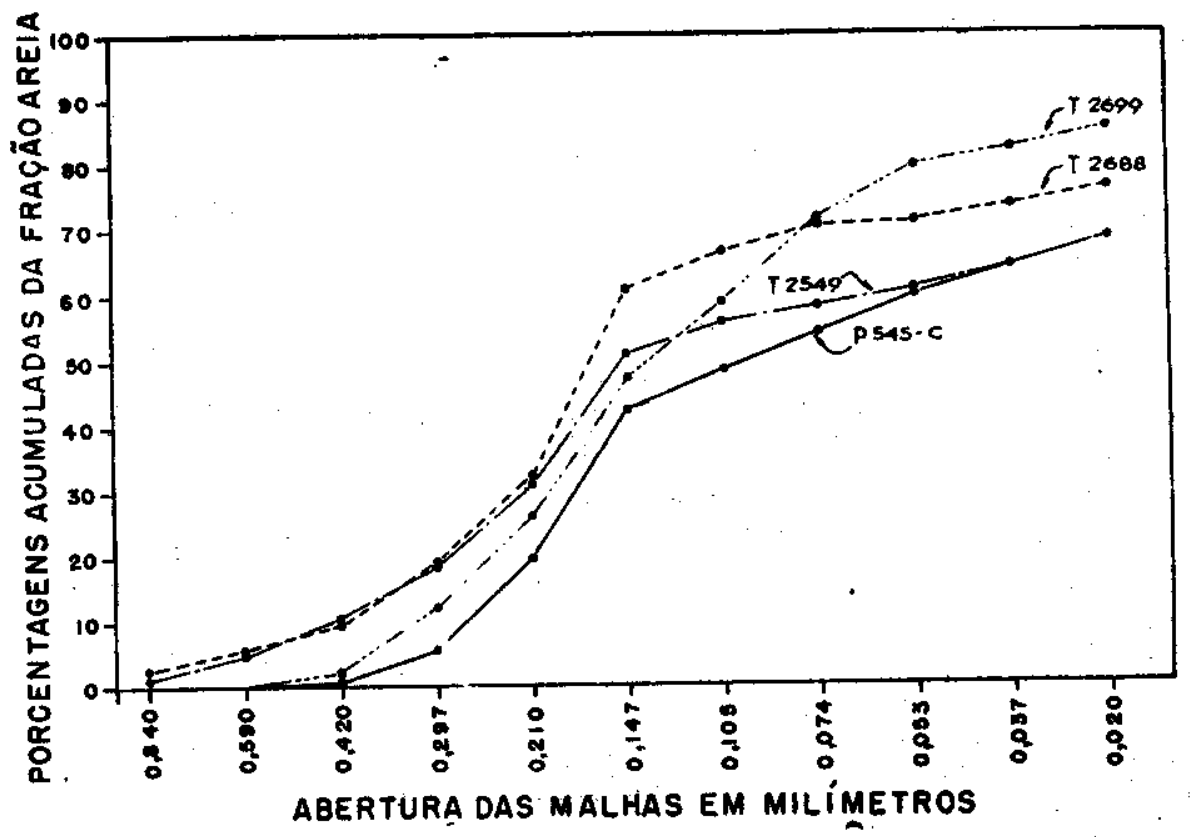

Figura 2. - Curvas acumulativas da fração areia de alguns tipos de solo do Estado de São Paulo: P 545-c - arenito Bauru; T 2549 - planalto de São Carlos; $T 2688$ - Serra de Santana; $T 2699$ - arenito Botueatu.

Pode-se observar, ainda, na figura 2, que a amostra T-2699 é bem mais arenosa do que as outras, diminuindo a porcentagem de $T-2688$ a $T-2549$ e a $P$-545c.

Comparando-se os totais de areia grossa e areia fina das amostras (quadro 2), com a distribuição granulométrica, representada nos histogramas e curvas acumulativas, percebe-se a precariedade das determinaçōes correntes para o conhecimento granulométrico da fração areia. Esses resultados indieam sạ a areia fina dominante, principalmente nas 
amostras $P$-545c e T-2699. Tomando como limite a posição da moda (quadro 4), constante para tôdas elas $(0,210-0,147 \mathrm{~mm})$, a situação é algo diversa.

Quadro 4. - Porcentagens em pêso dos grãos de areia, em relação à moda, nos solos: $P-545 c=$ arenito Bauru; $T-2549=$ planalto de São Carlos; $T$ - 2688 = Serra de Santane: $T-9699=$ arenito Botucatu

\begin{tabular}{|c|c|c|c|c|}
\hline Amostras & $\begin{array}{l}\text { Grãos maiores } \\
\text { que a moda }\end{array}$ & $\begin{array}{l}\text { Moda } \\
\text { inf. a } 0,210 \mathrm{~mm} \\
\text { sup. a } 0,147 \mathrm{~mm}\end{array}$ & $\begin{array}{l}\text { Grãos menores } \\
\text { que a moda }\end{array}$ & Total \\
\hline $\mathbf{P}-\mathbf{5 4 5 c} \ldots \ldots \ldots$ & 19,6 & 22,5 & 26,3 & 68,4 \\
\hline T-2549 $\ldots \ldots \ldots$ & 31,1 & 19,8 & 13,0 & 63,9 \\
\hline $\mathrm{T}-2688$ & 32,6 & 28,0 & 15,4 & 76,0 \\
\hline T-2699 & 26,3 & 21,0 & 37,8 & 85,1 \\
\hline
\end{tabular}

Sòmente na amostra $P-545 c$ a fração arenosa menor que a moda é nitidamente dominante. A amostra T-2699 apresenta um maior equilíbrio entre as frações finas e grosseiras, ao passo que nas restantes a fração grosseira é muito mais abundante. Fica evidenciada, também, a irregularidade da distribuição, exceção feita da $T-2699$.

Ao apreciar os resultados da análise estatística (quadro 3) deve-se lembrar que êles são calculados para a amostra total, silte e argila incluídos (3).

$O$ desvio aritmético dos quarté́s $(Q D a)$, mostra que o afastamento entre os quartéis e a mediana decresce sucessivamente de $T-2549$, para $T-2688, P-545 c$ e $T-2699$. Isso indica que a distribuição granulométrica, entre os limites dos quartéis, é mais larga em $T-2549$, diminuindo de amplitude para $T \cdot 2699$.

Úma da amostras é bem selecionada $(T-2699)$ ao passo que o coeficiente de seleção ( $S o$ ) das outras é normal $(T-2688)$ ou medíocre $(T-2549$ e $P-545 c)$. O índice de seleção dá idéia da distribuição, podendo-se concluir que a amostra $T-2699$ apresenta distribuição granulométrica mais homogênea e de menor amplitude.

A variacão de $s k a$, grau aritmético de simetria, indica que a amplitude da distribuição de duas amostras (T-2688 e T-2519) é maior do lado fino, ao passo que nas outras duas $(P-545 c$ e $T-2699)$ essa amplitude seria mais pronunciada do lado grcsseiro.

0 grau geométrico de assimetria $(S k)$, indica que a mediana de $T-2699$ se acha mais próxima da moda do que nas outras amostras. Os valôres de $S k$ decrescem de $T-2688$ para $T-2549$ e $P-545 c$, mostrando 
haver uma diminuição da homogeneidade da amostra, com maior afastamento da mediana do valor mais freqüente da distribuição.

Esses resultados confirmam as observaçóes feitas anteriormente, sôbre as diferenças encontradas na representação das amostras: $T-2699$ e $P-545 c$ possuem uma fração grosseira menos importante que $T-2688$ e $T-2549$. A repartição granulométrica de $T-2699$, mais homogênea, de menor amplitude, está mais próxima de uma curva de distribuição normal.

\section{4 - CONCLUSOES}

A aplicação de um método de estudo detalhado da fração areia, em alguns tipos de solos arenosos do Estado de São Paulo, permitiu ressaltar diferenças entre as suas distribuiģões granulométricas.

Os resultados são reprodutíveis a partir de 10 minutos de peneiragem. As diferenças verificadas pela variação do tempo de pẹneiragem são muito pequenas e sem influências para a apreciação dos resultados.

A expressão dos resultados, em freqüência ponderal, sofre restriçōes do ponto de vista hidrodinâmico, porém, é muito eficiente no tocante à análise das diferenças existentes entre as amostras.

Assim, a amostra proveniente de solo do arenito Botucatu apresenta uma distribuição mais regular, denotando maior homogeneidade. Todos os eálculos estatísticos comprovam essa observação.

A amostra proveniente de solo do arenito Bauru mostra maior amplitude da distribuição, porém, é mais regular do que as das amostras provenientes do planalto de São Carlos e da Serra de Santana.

Avulta a presença de maior quantidade de grãos grosseiros nas amostras da Serra de Santana e planalto de São Carlos. O emprêgo da análise estatística serve para ressaltar êsses aspectos.

\section{A METHOD FOR EVALUATING SAND PARTICLE SIZE DISTRIBUTION IN SOILS}

\section{SUMMARY}

A technique that.proved itself satisfactory for determining the sand particle size distribution in certain soils and for its numerical and graphical representation is described.

Samples from soils of the two most important sedimentary roeks of the state of São Panlo, "arenito Bauru" and "arenito Botueatu" were used, as well as soil samples from the "São Carlos" and "Santana" plateaus. A preliminary test was carried out to determine the minimum sieving period necessary for a satisfactory separation. Periods of 10,20 , and 30 minutes were compared and gave nearly the same results. For further determinations a 15 minute sieving period was used.

The sand particle size distribution of the "arenito de Botucatu" samples was more nniform and had a narrower range than the others. The distribution range of 
the samples widened in the following order: "Santana", "São Carlos", and "arenito de Pauru". The last sample had a more uniform size distribution than the other
two.

Fractions coarser than the mode predominated in the samples from "Santana" and from "São Carlos"; particles finer than the mode predominated in the "arenito de Bauru"; the fractions coarser and finer than the mode were about equal in the V

\section{LITERATURA CITADA}

1. BERTHOIS, L. Teenique de l'analyse granulométrique. P’aris, École Pratique des Hautes Études, Lab. Géom., 1956. Mém. 6. 76 p.

2. BJöRNBERG, A. J. S. Rochas elásticas do Planalto de Poęos de Caldas. São Paulo, Fac. Fil. Oiene. Let. Bol. 237. Geol. 18:(65).122. 1959.

3. CHRISTOFOLETTI, A. \& QUEIROZ, J. P. (NETO). Os sedimentos da Serra de Santana. Trabalho apresentado ao XIV Congresso Brasileiro de Geologia, Brasília, 1960. (A publiear). 4. DERRUAU, M. Préeis de Géomorphologie. Paris, Masson \& Cie., 1956.164
fig. 50 pl.

5. FREITAS, 'R. O. Sedimentação, estratigrafia e teetônica da séric BAURU (Eatado de 8ão Paulo). São Paulo, Fae. Fil. Cienc. Let. Bol. 194. Geol.
14. 1955. 185 p.

6. MEDINA, H. PENA. Contribuição ao estudo da análise granulométriea do solo. Trabalho apresentado ao vi Congresso Brasileiro de Ciência do Solo,
Salvador, Rahia, 1957. [Mimeografado].

7. PAIVA, J. E. (NETO), KƯPER, A. [e outros] Estudos pedológieos da Estação Experimental de Pindorama. [Não publicado]. 8. PETTIJOHN, F. J. Sedimentary Rocks. New York, Harper and Brothers,
1949.

9. TWENHOFEL, W. H. Principles of sedimentation. New York, MeGraw.Hill Book Co., Ine., 1939. $610 \mathrm{p}$.

10. \& TYLER, S. A. Methods of Study of Sediments. New York,
MeGraw.Hill Book Co, Ine., 1941. 183 p. 